\title{
In vivo and in vitro effects of statins on lymphocytes in patients with Hashimoto's thyroiditis
}

\author{
Sevim Gullu, Rifat Emral, Mehmet Bastemir, Arthur B Parkes ${ }^{1}$ and John H Lazarus ${ }^{1}$ \\ Ankara University, School of Medicine, Department of Endocrinology and Metabolic Diseases, Ibn-i Sina Hospital,10th floor, D-Block, O6100 Sihhiye, \\ Ankara, Turkey and ${ }^{1}$ School of Medicine, Cardiff University, Cardiff, UK
}

(Correspondence should be addressed to S Gullu; Email: gullu@medicine.ankara.edu.tr)

\begin{abstract}
Background: Statins have apoptotic effects on many cell types. Hashimoto's thyroiditis (HT) is an autoimmune disease in which cell-mediated autoimmune mechanisms are pathogenetically involved. Objective: The aim of this study was to evaluate the in vivo effects of Simvastatin on thyroid function, lymphocyte subtypes and also to investigate the apoptotic effects of Simvastatin, Mevastatin, Pravastatin and Cerivastatin on lymphocytes from patients with HT.

Methods: In the first part of the study, 11 patients with HT and subclinical hypothyroidism (SH) were given Simvastatin (20 mg/day) for 8 weeks. Ten patients with SH and HT served as the control group. No treatment was given to controls. Thyroid function, C-reactive protein (CRP) levels and lymphocyte subtypes of both groups were determined before the study and after 8 weeks. In the second part of the study, the apoptotic effects of statins on lymphocytes were evaluated in patients with HT $(n=10)$ and normal subjects $(n=10)$ in vitro. Apoptosis was investigated by using Annexin-V and propidium iodide. Lymphocytes from patients and controls were incubated with different concentrations of Simvastatin, Cerivastatin, Mevastatin and Pravastatin.

Results: An increase in serum free tri-iodothyronine and free thyroxine levels and a decrease in TSH levels were observed $(P<0.05)$ with Simvastatin treatment. CD4 + cells and B lymphocytes increased whilst CD8 + cells, natural killer cells and activated T lymphocytes decreased significantly in the treatment group $(P<0.05)$. The CRP level of the group also decreased with Simvastatin but it did not reach significance $(P=0.057)$. None of parameters was found to be different from the baseline in the control group. In in vitro experiments, apoptosis was observed in CD3 + (both in CD8 + and CD4 + cells) with all statins in both patient and control samples. Mevalonate, which was used in experiments, reversed apoptosis in some but not all samples.

Conclusions: The results of this study suggested that Simvastatin is an immune modulatory agent and improves thyroid function in patients with HT. This effect is probably mediated via lymphocyte apoptosis as demonstrated with in vitro experiments and is not confined to Simvastatin since Mevastatin, Pravastatin and Cerivastatin also induced apoptosis in lymphocytes.
\end{abstract}

European Journal of Endocrinology 153 41-48

\section{Introduction}

Hashimoto's thyroiditis (HT) is an inflammatory disorder of the thyroid gland characterized by an enlargement of the gland with lymphocytic infiltration, various degrees of thyroid hypofunction and circulating antibodies to thyroid antigens (1).

Thyroid cell destruction is observed in HT but there is debate regarding the exact mechanism of this destruction. Recently, a link with thyrocyte apoptosis has been observed (2-8). Although a B-cell response may have role in the process, a T-cell response is much more prominent in HT $(1,9-14)$. A large number of intrathyroidal lymphocytes in patients with HT are actually thyrocyte-specific cytotoxic $\mathrm{T}$ lymphocytes
(CTLs) $(10,12,13)$. Both CD8 + CTLs and CD4 + CTLs have a role in apoptosis through different pathways. Because CTLs kill target cells by inducing apoptosis and because increased apoptosis is observed in thyrocytes proximal to infiltrating lymphocytes, this activity has been proposed as a major mechanism for the thyrocyte destruction observed in HT $(2-14)$. In some studies, an increase in activated T cells, a decrease in $\mathrm{CD} 4 / \mathrm{CD} 8$ ratio, an increase in proliferative response to mitogens and an increase in natural killer cell activity have been demonstrated in patients with HT (14-24). In HT, the immunologic attack appears to be typically aggressive and destructive (1).

Statins competitively inhibit 3-hydroxy-3-methylglutaryl-coenzyme A (HMG-CoA) reductase activity and 
reduce mevalonate synthesis (25-27). As mevalonate and other intermediates of cholesterol synthesis (isoprenoids) are necessary for cell proliferation and other important cell functions, the effects of statins, other than cholesterol reduction, can be expected and this has been confirmed by recent studies $(27-47)$. Statins inhibit the proliferation and migration of vascular smooth muscle cells and macrophages. They also sensitize human smooth muscle cells to apoptosis and affect vascular endothelial cells $(26,27,30,31,33,35,36)$. Their growth arrest and apoptotic properties in some benign and malignant cells, including breast cancer, prostate cancer, prostate hyperplasia, renal mesangial cells, neuroblastoma, leukaemic cells, malignant mesothelioma and malignant glioma cells, have been reported (27-30). Statins may also induce apoptosis in proliferating thyroid cells and in thyroid cancer cells $(37-40)$.

Some recent clinical trials indicate that statins have immunomodulatory effects $(41-47)$. As a result of immunosuppressive actions, statins may also reduce the incidence of rejection following organ transplantation in some inflammatory and autoimmune disorders $(41-43)$. The cytotoxicity of natural killer cells was found to be lower in patients taking statin (30, $44,47)$. Inhibition of lymphocyte proliferation responses to non-specific mitogens has also been reported (44-47). Reduction in C-reactive protein (CRP), an acute phase protein, has also been reported in some studies (34).

Since T lymphocyte response is thought to be the major factor responsible for thyroid cell destruction in HT and some degree of altered lymphocyte numbers, lymphocyte and natural killer cell function can be seen in these patients and, since statins appear to have an inhibitory effect on lymphocytes, it is logical to consider whether statins could have some effects on disease progression in HT.

The aim of this study was to investigate the effects of Simvastatin, an HMG-CoA reductase inhibitor, on thyroid function, lymphocyte function and the distribution of lymphocyte subtypes in patients with HT. The in vitro effects of Pravastatin, Cerivastatin, Mevastatin and Simvastatin on lymphocytes from patients with HT were also investigated.

\section{Materials and methods}

\section{Part 1: clinical trial}

Patients and methods Twenty-one patients with HT (19 women and two men) aged between 28 and 48 years were included in the study. All the patients had had primary subclinical hypothyroidism for at least 6 months prior to the study and were not taking any medications including thyroid hormones. Diagnostic criteria for subclinical hypothyroidism were an elevated serum thyrotrophin (TSH) level with normal serum free thyroxine (FT4) and free tri-iodothyronine (FT3) levels. The diagnosis of HT was made by the existence of a firm goiter, thyroid dysfunction, elevated anti-thyroid peroxidase (anti-TPO) and/or anti-thyroglobulin (anti-Tg) antibodies, a low ultrasonographic echogenity of the gland and demonstration of lymphocytic infiltration by fine-needle aspiration biopsy. Patients with other medical diseases or using drugs for any other conditions were excluded from the study. The study was approved by the local ethical committee and informed written consent was obtained from the patients.

Serum TSH, FT4, FT3, anti-TPO and anti-Tg antibody levels, CRP levels, percentages of T lymphocytes (T-suppressor and T-helper), natural killer cells, B lymphocytes and activated $\mathrm{T}$ lymphocytes of the patients were measured. After these baseline evaluations patients were randomly assigned into two groups. Simvastatin was started at a dosage of $20 \mathrm{mg} /$ day to 11 patients (Simvastatin group). No treatment was given to ten patients (control group). All the parameters were re-evaluated after 8 weeks in both groups. Lymphocyte subtype analyses were done by the same technician who was blinded to the patient groups.

Serum FT4, FT3 and TSH levels were measured using a chemiluminescence immunoassay kit (ACS:180; Chiron Diagnostics, Bayer Corporation, New york, NY, USA). Anti-TPO and anti-Tg levels were measured by RIA (Brahms Diagnostics GMBH, Berlin, Germany). Lymphocyte subpopulations were evaluated by flow cytometry. Proportions of T-helper cells (CD3 + CD $4+$ ), T-suppressor/cytotoxic cells $(\mathrm{CD} 3+\mathrm{CD} 8+)$, B lymphocytes $(\mathrm{CD} 3(\mathrm{CD} 19+), \quad$ natural killer cells $(\mathrm{CD} 3(\mathrm{CD} 16+\mathrm{CD} 56+)$ and activated $\mathrm{T}$ lymphocytes $(\mathrm{CD} 3+\mathrm{CD} 25+)$ were measured busing a FacSort machine (Becton-Dickinson Co., Franklin Lakes, NJ, USA). The transfered data were then analyzed using the Win MDI 2.8 software (provided by J Trotter, Scripps Research Institute, La Jolla, CA, USA). T lymphocytes were gated on the basis of their staining characteristics.

Statistical analysis Data are given as a means \pm S.D. or as median. The paired t-test, Wilcoxon matchedpairs test or Mann-Whitney U test were used for statistical analysis. $P$ values less than 0.05 were accepted as indicating statistical significance.

\section{Part 2: in vitro experiments}

Cell isolation Blood samples were obtained from ten untreated patients with subclinical hypothyroidism and HT. Ten healthy sex- and age-matched subjects served as the control group. Peripheral blood mononuclear cells were isolated from the blood by histopaque (Sigma Chemical Co., St Louis, MO, USA) density-gradient centrifugation. After three washes in RPMI 1640 (Gibco-BRL, Grand Island, NY, USA), cells were frozen and stored in liquid nitrogen prior to assay. Cells were used for flow cytometry. 
Monoclonal antibodies Allophycocyanin (APC)labelled CD3 (T cells) (Immunotech, Marseille, France), R-phycoerythrin cyanin-labelled CD8 (cytotoxic T cells) (Immunotech), R-phycoerythrin-labelled CD4 (T-helper cells) (Immunotech), fluorescein isothiocyanate (FITC)labelled Annexin-V (early apoptosis marker) (Immunotech) were used for flow cytometry analysis using a FACScan flow cytometer (Becton Dickinson Co.).

Drugs Pravastatin (a gift from Bristol-Myers Squibb, Hounslow, UK) and Cerivastatin (a gift from Bayer, Midglamorgan, Glamorgan, UK) were dissolved in RPMI 1640. Simvastatin (a gift from Merck Sharp and Dohme, Leopardstown, Dublin, Southern Ireland) was dissolved in ethanol. Mevastatin was purchased (Sigma Chemical Co., Gillingham, Dorset, UK) and dissolved in ethanol. Mevalonate was obtained from Sigma Chemical Co. (UK).

Flow cytometry analyses Cytofluorometric estimation of lymphocyte subsets and apoptosis was performed as follows. Cells were taken from storage in liquid nitrogen and defrosted rapidly. After washing three times with RPMI 1640, cells were resuspended in RPMI 1640 containing 10\% heat-inactivated fetal calf serum, $2 \mathrm{mmol} / \mathrm{l}$ L-glutamine, penicillin $(100 \mathrm{U} / \mathrm{ml})$ and streptomycin $(100 \mu \mathrm{g} / \mathrm{ml})$ and were seeded at a density of $0.5-$ $2 \times 10^{6}$ cells $/ \mathrm{ml}$ in 24-well plates. Cells were incubated at $37^{\circ} \mathrm{C}$ in a humidified atmosphere containing $5 \%$ $\mathrm{CO}_{2}$ without or with different concentrations of drugs for $72 \mathrm{~h}$ (final concentrations of 10, 50, $100 \mu \mathrm{mol} / \mathrm{l}$ for Simvastatin, Pravastatin and Mevastatin and 10, 50, $100 \mathrm{nmol} / \mathrm{l}$ for Cerivastatin). Mevalonate was added to culture medium at a final concentration of $100 \mu \mathrm{mol} / \mathrm{l}$ in the different experiments.

For apoptosis and cell death analysis, cells were removed from culture and put into the tubes (100 $\mu \mathrm{l} /$ tube). Labelled CD3, CD4 and CD8 were added to the tubes and cells were incubated for $15 \mathrm{~min}$ in the dark at room temperature (RT). After washing with phosphate-buffered saline containing $0.1 \%$ bovine serum albumin, cells were re-suspended in $100 \mu \mathrm{l}$ Annexin V-binding buffer and incubated with Annexin V-FITC for $15 \mathrm{~min}$ in the dark at RT. Cell membrane permeability was assessed by determining the ability of cells to exclude the DNA-binding fluorescent dye, propidium iodide (PI). To distinguish cells that had lost membrane integrity, PI was added to a final concentration of $10 \mu \mathrm{g} / \mathrm{ml} 10 \mathrm{~min}$ before analysis. Twenty thousand cells were counted in each analysis.

\section{Results}

\section{Clinical study}

Demographic characteristics of the patients are given in Table 1. No statistical differences were seen between the data for the treatment and control groups of patients.
Table 1 Demographic characteristics of the patients. Data are given as means \pm S.D. for age, FT3 and FT4 and as median for TSH.

\begin{tabular}{lccc}
\hline & Control group & Simvastatin group & $\boldsymbol{P}$ \\
\hline Number (F/M) & $10(9 / 1)$ & $11(10 / 1)$ & \\
Age (years) & $32 \pm 4$ & $34 \pm 3$ & NS \\
FT3 (pmol/l) & $4.5 \pm 0.58$ & $4.18 \pm 0.28$ & NS \\
FT4 (pmol/l) & $12.4 \pm 1.9$ & $13.2 \pm 1.7$ & NS \\
TSH (mlU/ml) & $7.3(5.8-13.4)$ & $7.7(6.3-14.6)$ & NS \\
$\quad$ (range) & & & \\
\hline
\end{tabular}

NS, not significant.

Data for the Simvastatin and control groups, both before and after 8 weeks of treatment, are given in Table 2. Mean serum FT3 (4.62 \pm 0.39 vs $4.18 \pm 0.28 \mathrm{pmol} / \mathrm{l}, P<0.05)$ and FT4 levels $(14.8 \pm 2.5$ vs $13.2 \pm 1.7 \mathrm{pmol} / \mathrm{l}, P<0.05)$ increased and median serum TSH level (4.6 vs $7.7 \mathrm{mIU} / \mathrm{l}, P<0.05$ ) decreased with Simvastatin treatment. Although there were decreases in anti-TPO and anti-Tg antibody levels, these did not reach statistical significance. An increase in $\mathrm{CD} 4+$ and a decrease in CD8 + lymphocytes numbers were observed $(47 \pm 5$ vs $44 \pm 6 \%, P<0.05 ; 32 \pm 9$ vs $25 \pm 4 \%, P<0.05$ respectively). The $\mathrm{CD} 4$ to $\mathrm{CD} 8$ ratio also increased with therapy $(1.8 \pm 0.31$ vs $1.4 \pm 0.45$, $P<0.05)$. A significant increase in B lymphocyte number accompanied by a decrease in natural killer cell and activated $\mathrm{T}$ lymphocyte numbers was also detected $(P<0.05$ for all; Table 2$)$. The mean CRP level decreased with Simvastatin but it was not significant (3.4 \pm 0.46 vs $6.5 \pm 4.8 \mathrm{mg} / \mathrm{l}, P=0.057$ ).

None of the parameters changed in the non-treated control group (Table 2).

\section{In vitro apoptosis experiments}

To evaluate whether HMG-CoA reductase inhibitors (statins) induce apoptosis in lymphocytes, lymphocytes from a separate group of normal subjects and patients with HT were cultured in vitro and exposed to different concentrations of Pravastatin, Mevastatin, Cerivastatin and Simvastatin for $72 \mathrm{~h}$. To exclude the possibility that statins exerted a direct cytotoxic effect on the lymphocytes, cells were simultaneously treated with exogenous mevalonate, the product of HMG-CoA reductase, in some experiments. Statin treatment was associated with an increase in Annexin-V-positive cells (early apoptotic) and/or Annexin-V- and PI-positive cells (late apoptotic) in both control and patient lymphocytes in a dose-dependent manner (Table 3) in some samples. The percentages of CD3-positive cells undergoing apoptosis in the presence of Cerivastatin, Simvas-

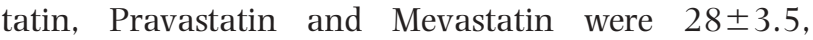
$30 \pm 2.5,26 \pm 3.7$ and $27 \pm 4.1$ respectively.

Although the number of apoptotic samples were slightly higher in the Cerivastatin and Simvastatin 
Table 2 Laboratory findings of the patients before and after study. Data are given as means \pm S.D. except medians for TSH and thyroid autoantibodies.

\begin{tabular}{|c|c|c|c|c|c|c|}
\hline & \multicolumn{3}{|c|}{ Control group $(n=10)$} & \multicolumn{3}{|c|}{ Simvastatin group $(n=11)$} \\
\hline & Before & After & $P$ & Before & After & $P$ \\
\hline FT3 (pmol/l) & $4.5 \pm 0.58$ & $4.5 \pm 0.84$ & NS & $4.18 \pm 0.28$ & $4.62 \pm 0.39$ & $<0.05$ \\
\hline FT4 (pmol/l) & $12.4 \pm 1.9$ & $13.2 \pm 1.9$ & NS & $13.2 \pm 1.7$ & $14.8 \pm 2.5$ & $<0.05$ \\
\hline $\mathrm{TSH}(\mathrm{mlU} / \mathrm{ml})$ (range) & $7.3(5.8-13.4)$ & $7.8(6.1-12.8)$ & NS & $7.7(6.3-14.6)$ & $4.6(2.8-8.9)$ & $<0.05$ \\
\hline Anti-TPO (range) & $1162(138-4326)$ & $1054(96-4957)$ & NS & $1216(166-4594)$ & $365(58-4136)$ & NS \\
\hline Anti-Tg (range) & $79(36-224)$ & $86(38-265)$ & NS & $102(49-286)$ & $56(27-229)$ & NS \\
\hline B cells $(\%)$ & $11.3 \pm 5$ & $11.0 \pm 5.4$ & NS & $9.7 \pm 2.2$ & $11.5 \pm 2.2$ & $<0.05$ \\
\hline $\mathrm{T}$ cells $(\%)$ & $72 \pm 8$ & $73 \pm 8$ & NS & $72 \pm 7$ & $72 \pm 8$ & NS \\
\hline $\mathrm{CD} 4+(\%)$ & $45 \pm 6$ & $44 \pm 6$ & NS & $44 \pm 6$ & $47 \pm 5$ & $<0.05$ \\
\hline $\mathrm{CD} 8+(\%)$ & $28 \pm 6$ & $30 \pm 6$ & NS & $32 \pm 9$ & $25 \pm 4$ & $<0.02$ \\
\hline CD4/CD8 & $1.6 \pm 0.49$ & $1.5 \pm 0.38$ & NS & $1.4 \pm 0.45$ & $1.8 \pm 0.31$ & $=0.006$ \\
\hline Activated T (\%) & $15.3 \pm 11.7$ & $14.5 \pm 10.1$ & NS & $13.4 \pm 8.3$ & $8.7 \pm 6.1$ & $=0.05$ \\
\hline Natural killer (\%) & $16.3 \pm 6.3$ & $16.3 \pm 6.3$ & NS & $19.6 \pm 7.6$ & $15.4 \pm 7.3$ & $<0.05$ \\
\hline $\mathrm{CRP}(\mathrm{mg} / \mathrm{l})$ & $3.65 \pm 1.69$ & $3.8 \pm 1.75$ & NS & $6.5 \pm 4.8$ & $3.4 \pm 0.46$ & $=0.057$ \\
\hline
\end{tabular}

NS, not significant.

experiments than in the Pravastatin and Mevastatin experiments, no difference could be found between patients and controls with any of the four statins.

Both CD3 + and CD3 - cells showed apoptosis in the experiments. $\mathrm{CD} 4+$ and $\mathrm{CD} 8+$ cells were also affected similarly and decreases in both cell types were observed in the samples in which statins induced apoptosis. Apoptosis in CD3 + cells are given in Figs 1 and 2. Apoptosis was observed with all statins in both patient and control samples in different proportions. Increases in Annexin-V-positive cells are given in Fig. 3.

Mevalonate at a concentration of $100 \mu \mathrm{mol} / \mathrm{l}$ prevented a cytotoxic effect of the statins in some experiments, suggesting that the effects of statins were indeed related to the inhibition of the mevalonate pathway. Inhibition of apoptosis by mevalonate is also shown in Figs 1 and 2.

\section{Discussion}

In the clinical part of the present study, Simvastatin, an HMG-CoA inhibitor, changed the distribution of the lymphocyte subpopulations in a group of patients with HT. Along with these alterations, an improvement in the thyroid function was also demonstrated. We have

Table 3 Number of lymphocyte samples that showed apoptosis in patients with $\mathrm{HT}$ and controls (in vitro experiments).

\begin{tabular}{lcc}
\hline & \multicolumn{2}{c}{$\begin{array}{c}\text { No. of samples with } \\
\text { apoptosis/total no. }\end{array}$} \\
\cline { 2 - 3 } & Patients & Control \\
\hline Pravastatin & $6 / 10$ & $5 / 10$ \\
Cerivastatin & $8 / 10$ & $7 / 10$ \\
Mevastatin & $4 / 10$ & $4 / 10$ \\
Simvastatin & $8 / 10$ & $8 / 10$ \\
\hline
\end{tabular}

also shown that Simvastatin, Cerivastatin, Mevastatin and Pravastatin induced apoptosis in peripheral blood $\mathrm{T}$ lymphocytes from some normal individuals and some patients with HT in vitro.

HT may manifest as hypothyroidism that is accompanied by massive infiltration of lymphoid cells (1). A large number of the intrathyroidal lymphocytes in patients with HT are thyrocyte-specific CTLs (1012). In HT, increased apoptosis of the thyrocytes has been proposed as the mechanism of thyroid destruction characteristic of the disease (2-8). CD8 + CTLs and CD4 + CTLs have been proposed to play role in cytokine-mediated thyrocyte apoptosis in HT (1-8). It seems that cytokines, produced by the intrathyroidal lymphocytes, up-regulate apoptosis via increasing the expression of proteins that have a role in the apoptotic pathways.

Statins are used clinically for lowering hypercholesterolaemia because of their inhibitory effect on hepatic biosynthesis of cholesterol at the mevalonate step (25). Recently, however, it was found that their effects are not limited to lipid lowering (26-48). Apoptotic effects of the drugs on several cell lines have been demonstrated. Anti-inflammatory effects, including decreases in acute phase proteins, have also been found in some patient groups, especially in patients with atherosclerosis (34). Inhibition of leukocyte rolling, adherence and transmigration in acute inflammatory states, inhibition of chemotaxis by monocytes, regulation of natural killer cell cytotoxicity and inhibition of antibody-dependent cellular cytotoxicity have been reported $(41-47)$.

In contrast to a study reporting no change in total lymphocyte numbers and lymphocyte subtypes, performed in hypercholesterolaemic subjects with Lovastatin (49), we found changes in lymphocyte subtypes with Simvastatin in patients with HT. Similar to our results, the effects of statins on lymphocyte functions have been reported previously $(50-53)$. Decreases in 


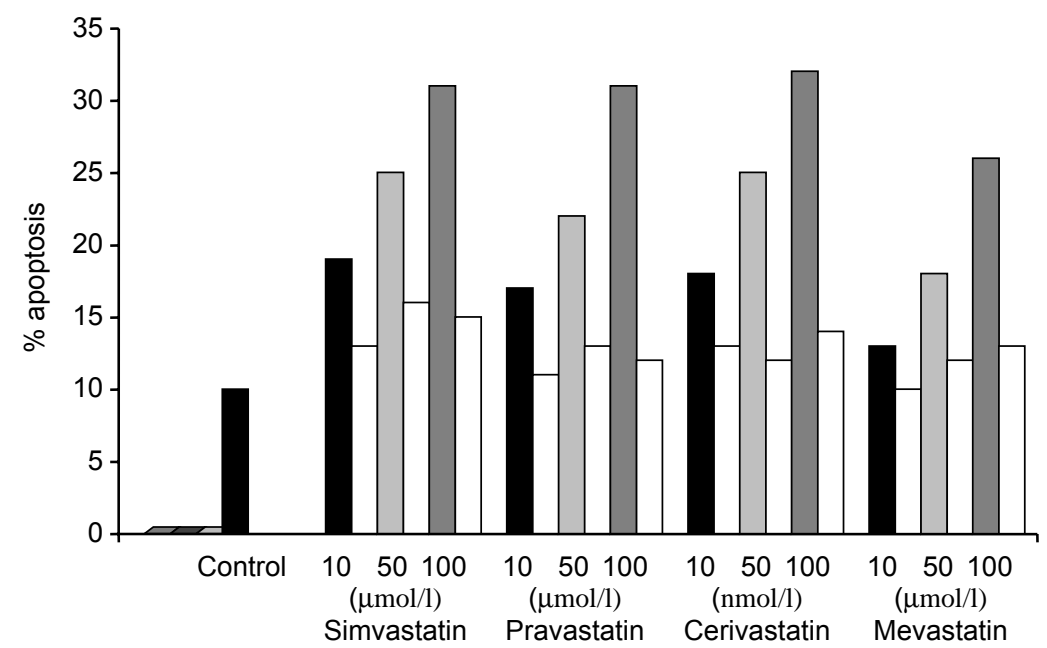

Figure 1 CD4 + cell apoptosis with statins in a typical patient. The control bar represents the cells incubated without any drug. The open bars show the data obtained with cells incubated with mevalonate.
CD8 + lymphocytes, activated T lymphocytes, natural killer cells and CRP levels and improvement in thyroid function in our study have suggested that these drugs have immune modulatory effects. Although it is difficult to make a strong suggestion with the rather small number of patients in our study, improvement in thyroid function was probably mediated through apoptosis of the lymphocytes as indicated by the present in vitro study. Although only Simvastatin was used for the clinical trial, the effect does not appear to be confined to Simvastatin since Cerivastatin, Mevastatin and Pravastatin also showed apoptotic effects on lymphocytes in vitro.

The first direct scientific and mechanistic evidence that statins might have a role in immunomodulation indicated that statins inhibited the expression of major histocompatibility complex class II genes $(47,54)$. This finding led to the suggestion that statins might become novel therapeutic agents in the area of immunosuppression, anti-inflammation and immune-related disorders such as auto-immune diseases (47). Several publications have identified a therapeutic use for statins in the treatment of multiple sclerosis, rheumatoid arthritis, autoimmune encephalomyelitis (42, 43, 55, 56). Statins have also been found to be beneficial in decreasing the rejection rates and graft survival in organ transplantation $(41,44)$. To our knowledge, this is the first study to show in vivo and in vitro effects of statins on lymphocytes and thyroid functions in patients with HT. We observed improvements in the thyroid function tests in patients with HT and subclinical hypothyroidism with Simvastatin treatment. If this observation is validated, statins may become the drug of choice in the treatment of hyperlipidaemic patients with subclinical hypothyroidism, in whom thyroxine therapy may not be safe. However, since the number of patients in the clinical part of the study was small and the study was conducted in an open rather than a placebo-controlled manner, it is obvious that longitudinal placebo-controlled double-blind studies with a larger patient population are now required to determine the role of statins in the treatment of HT.

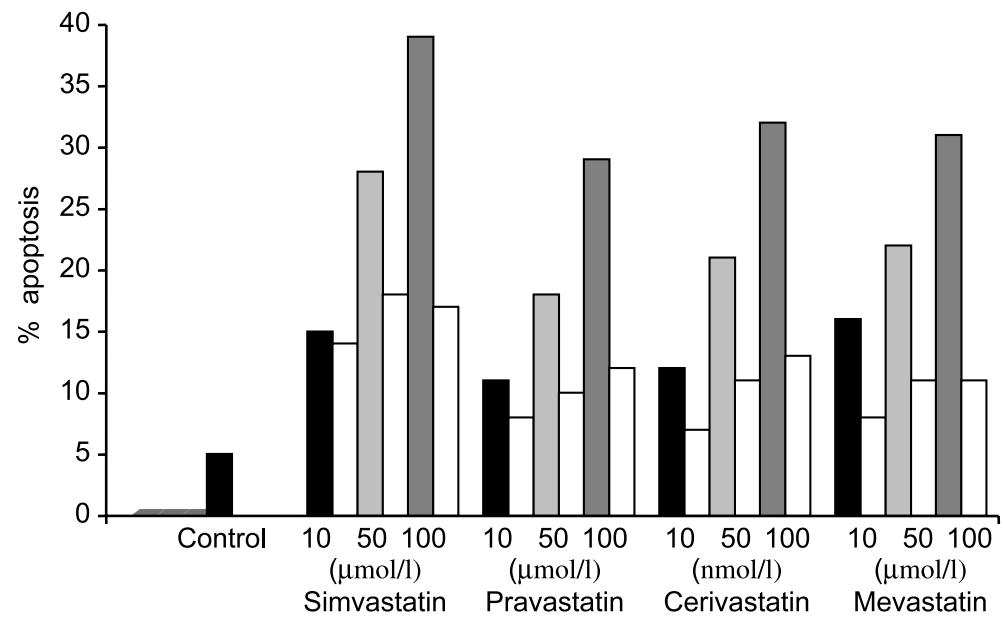

Figure 2 CD8 + cell apoptosis with statins in a typical patient. The control bar represents the cells incubated without any drug. The open bars show the data obtained with cells incubated with mevalonate. 
A

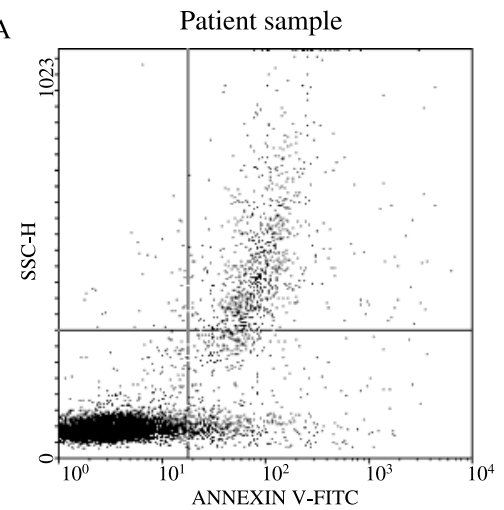

C

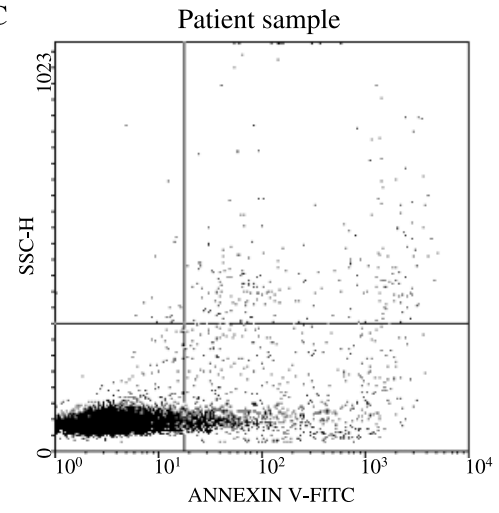

B

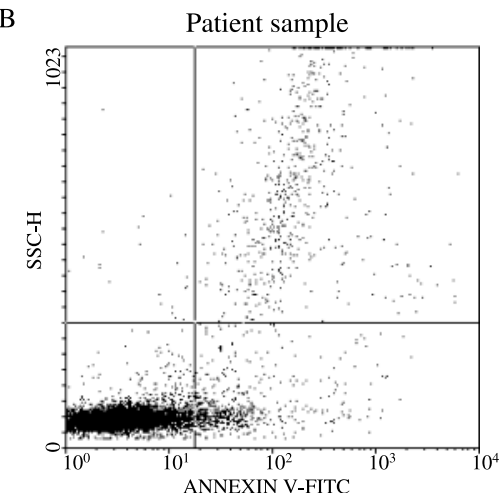

$\mathrm{D}$

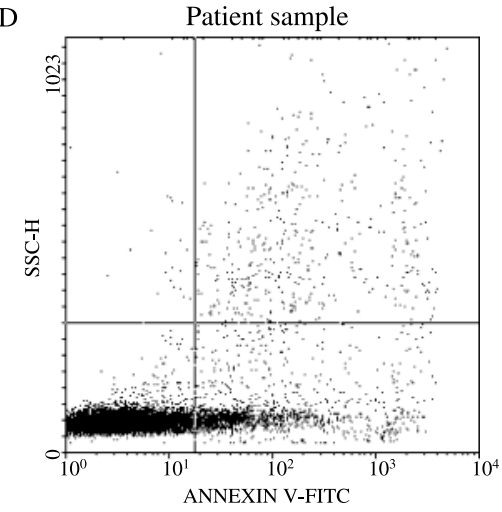

Figure 3 Graphical output from the FACScan analyzer. Before analysis, lymphocytes were stained with CD3-APC mouse antihuman CD3 and FITC-labelled Annexin- $V$ was used as apoptosis marker. (A) Cells without any drug, (B) cells plus $10 \mu \mathrm{mol} / \mathrm{l}$ Simvastatin, (C) cells plus $50 \mu \mathrm{mol} / \mathrm{l}$ Simvastatin and (D) cells plus $100 \mu \mathrm{mol} / \mathrm{l}$ Simvastatin. Increases in Annexin-V-positive cells with the increases in drug concentration can be seen in the lower right quadrants. SSC, side scatter.
CD4 + cells and B lymphocytes showed increases in the clinical study but, on the contrary, increases in apoptosis in these subtypes were found in the in vitro part of the study. Although it is difficult to explain this discrepancy, it may be related to the methods used in in vivo and in vitro experiments. Another explanation for the discrepancy may be that HT is accepted as a Th1-mediated disease and, in a very recent study (50), inhibition of HMG-CoA reductase reduced Th1 and promoted Th2 development, which may, in part, explain our results. We did not analyse the Th subtypes but it may be speculated that the increase observed in our in vivo study might result from an increase in Th2 cells.

Apoptosis could not be demonstrated in some samples in the present study and mevalonate did not inhibit the apotosis in some samples. The latter finding suggests that mechanisms other than inhibition of the mevalonate pathway have a role in the lymphocyte apoptosis with statins. Why did apoptosis not occur in every sample with statins? It might be speculated that lymphocytes may have been resistant to statins in some individuals.

In conclusion, statins may alter the number and type of lymphocyte through apoptosis and may improve thyroid functions in patients with HT. These newly observed effects may represent a new strategy for treatment of cell-mediated autoimmune diseases including HT. The preliminary data of this study provide some evidence that statins may also have immunomodulatory properties in addition to their lipid-lowering effects in patients with HT, but larger scale, randomized, double-blind trials are needed to validate the role of statins for the treatment of this autoimmune disease.

\section{Acknowledgements}

This work was supported by a grant from the Wales Office of Research and Development for Health and Social Care, National Assembly for Wales. We thank Lynn Taylor for laboratory assistance and we are grateful to Terry Hoy for help with FACS analysis.

\section{References}

1 Weetman AP \& McGregor AM. Autoimmune thyroid disease: developments in our understanding. Endocrine Reviews 199415 788-802.

2 Ludgate M \& Jasani B. Apoptosis in autoimmune and non-autoimmune thyroid disease. Journal of Pathology $1997 \mathbf{1 8 2}$ 123-124.

3 Phelps E, Wu P, Bretz J \& Baker JR. Thyroid cell apoptosis. A new understanding of thyroid autoimmunity. Endocrinology and Metabolism Clinics of North America 200029 375-388.

4 Hammond LJ, Palazzo FF, Shattock M, Goode AW \& Mirakian R. Thyrocyte targets and effectors of autoimmunity: a role for death receptors? Thyroid $200111919-927$. 
5 Bretz JD \& Baker JR Jr. Apoptosis and autoimmune thyroid disease: following a TRAIL to thyroid destruction? Clinical Endocrinology $2001551-11$.

6 Stassi G \& De Maria R. Autoimmune thyroid disease: new models of cell death in autoimmunity. Nature Reviews of Immunology 2002 2 195-204.

7 Andrikoula M \& Tsatsoulis A. The role of Fas-mediated apoptosis in thyroid disease. European Journal of Endocrinology $2001 \mathbf{1 4 4}$ $561-568$.

8 Yamazaki H, Bretz JD, Arscott PL \& Baker JR. Apoptosis and the thyroid: the cell biology and potential implications for thyroid disease. Current Opinions in Endocrinology and Diabetes 20007 260-264.

9 Leyendeckers H, Voth E, Schicha H, Hunzelmann N, Banga P \& Schmitz J. Frequent detection of thyroid peroxidase-specific IgG + memory B cells in blood of patients with autoimmune thyroid disease. European Journal of Immunology $20023 \mathbf{2}$ 3126-3132.

10 Del Prete GF, Vercelli D, Tiri A, Maggi E, Mariotti S, Pinchera A, Ricci M \& Romagnani S. In vivo activated cytotoxic $\mathrm{T}$ cells in the thyroid infiltrate of patients with Hashimoto's thyroiditis. Clinical and Experimental Immunology 198665 140-147.

11 MacKenzie WA, Schwartz AE, Friedman EW \& Davies TF. Intrathyroidal T cell clones from patients with autoimmune thyroid disease. Journal of Clinical Endocrinology and Metabolism 1987 $64818-824$.

12 Watanabe M, Yamamoto N, Maruoka H, Tamai H, Matsuzuka F, Miyauchi A \& Iwatani Y. Independent involvement of CD8 + CD25 + cells and thyroid autoantibodies in disease severity of Hashimoto's disease. Thyroid 200212 801-808.

13 Roura-Mir C, Catalfamo M, Sospedra M, Alcalde L, Pujol-Borrell R \& Jaraquemada D. Single-cell analysis of intrathyroidal lymphocytes shows differential cytokine expression in Hashimoto's and Graves' disease. European Journal of Immunology $1997 \quad 27$ 3290-3302.

14 Wilfing A, Gessl A, Czernin S, Forster O \& Grubeck-Loebenstein B. $\mathrm{T}-\mathrm{T}$ cell interactions in patients with endocrine autoimmunity. Definition of antiergotypic T lymphocytes. Hormone and Metabolic Research 199325 628-631.

15 Yoshikawa N, Morita T, Resetkova E, Arreanza G, Carayon P \& Volpe R. Reduced activation of suppressor T lymphocytes by specific antigens in autoimmune thyroid disease. Journal of Endocrinological Investigation 199316 609-617.

16 Liakata E, Philippou G, Souvatzoglou A, Lymberi P \& Carayanniotis G. Assessment of the frequency of mutant (hprt-) T lymphocytes from peripheral blood of patients with Hashimoto's thyroiditis. Thyroid $200313631-636$.

17 Martin A \& Davies TF. T cells and human autoimmune thyroid disease: emerging data show lack of need to invoke suppressor T cell problems. Thyroid 19922 247-261.

18 Ohashi H, Okugawa T \& Itoh M. Circulating activated T cell subsets in autoimmune thyroid diseases: differences between untreated and treated patients. Acta Endocrinologica 1991125 502-509.

19 Zeki K, Fujihira T, Shirakawa F, Watanabe K \& Eto S. Existence and immunological significance of circulating $\mathrm{Ia}+\mathrm{T}$ cells in autoimmune thyroid diseases. Acta Endocrinologica $1987 \mathbf{1 1 5}$ $282-288$.

20 Row VV \& Volpe R. In vitro regulation of antithyroglobulin synthesis by lymphocytes of patients with Hashimoto's disease by an antigen-specific 'suppressor factor' derived from cultured normal human T-lymphocytes. Journal of Clinical and Laboratory Immunology 198621 159-163.

21 Chan JY \& Walfish PG. Activated $(\mathrm{Ia}+)$ T-lymphocytes and their subsets in autoimmune thyroid diseases: analysis by dual laser flow microfluorocytometry. Journal of Clinical Endocrinology and Metabolism $1986 \mathbf{6 2} 403-409$.

22 Endo Y, Aratake Y, Kotani T, Kuribayashi T, Tamura K \& Ohtaki S. Increase in autorosette-forming lymphocytes in thyroid diseases. Endocrinologia Japonica $198431627-634$.
23 Iwatani Y, Amino N, Mori H, Asari S, Izumiguchi Y, Kumahara Y \& Miyai K. T lymphocyte subsets in autoimmune thyroid diseases and subacute thyroiditis detected with monoclonal antibodies. Journal of Clinical Endocrinology and Metabolism $1983 \mathbf{5 6}$ 251-254.

24 Canonica GW, Bagnasco M, Corte G, Ferrini S, Ferrini O \& Giordano G. Circulating T lymphocytes in Hashimoto's disease: imbalance of subsets and presence of activated cells. Clinical Immunology on Immunopathology 198223 616-625.

25 Clearfield MB. Statins: balancing benefits, efficacy and safety. Expert Opinion on Pharmacotherapy 20023 469-477.

26 Mason JC. Statins and their role in vascular protection. Clinical Sciences $2003 \mathbf{1 0 5} 251-266$.

27 Bellosta S, Ferri N, Bernini F, Paoleti R \& Corsini A. Non-lipidrelated effects of statins. Annals of Medicine 200032 164-176.

28 Kaushal V, Kohli M, Mehta P \& Mehta JL. Potential anticancer effects of statins: fact or fiction? Endothelium $2003 \mathbf{1 0 ~ 4 9 - 5 8 . ~}$

29 Chan KK, Oza AM \& Siu LL. The statins as anticancer agents. Clinical Cancer Research 20039 10-19.

30 Bocan TM. Pleiotropic effects of HMG-CoA reductase inhibitors. Current Opinion in Investigational Drugs $200231312-1317$.

31 Chan H, Ikeda U, Shimpo M \& Shimeda K. Direct effects of statins on cells primarily involved in atherosclerosis. Hypertension Research 200023 187-192.

32 Knapp AC, Huang J, Starling G \& Kiener PA. Inhibitors of HMGCoA reductase sensitize human smooth muscle cells to fasligand and cytokin induced cell death. Atherosclerosis $2000 \mathbf{1 5 2}$ 217-227.

33 Guijarro C, Blanco-Colio LM, Massy ZA, O’Donnell MP, Kasiske BL, Keane WF \& Egido J. Lipophylic statins induce apoptosis of human vascular smooth muscle cells. Kidney International $19997 \mathbf{1}$ (Suppl) S8-S9.

34 Kluft C, Maat MPM, Leuven JAG, van Loon BJP \& Mohrschladt MF. Statins and C-reactive protein. Lancet 19993531274.

35 Guijarro C, Blanco-Colio LM, Ortego M, Alonso C, Ortiz A, Plaza JJ, Diaz C, Hernandez G \& Edigo J. 3-Hydroxy-3-methylglutaryl-CoA reductase and isoprenylation inhibitors induce apoptosis of vascular smooth muscle cells in culture. Circulation Research $1998 \mathbf{8 3}$ 490-500.

36 Hernandez-Perera O, Perez-Sala D, Navarro-Antolin J, SanchezPascuala R, Hernandez G, Diaz C \& Lamas S. Effects of the 3hydroxy-3-methylglutaryl-CoA reductase inhibitors, atorvastatin and simvastatin, on the expression of endothelin-1 and endothelial nitric oxide synthase in vascular endothelial cells. Journal of Clinical Investigation $1998 \mathbf{1 0 1} 2711-2719$.

37 Vitale M, Di Matola T, Rossi G, Laezza C, Fenzi G \& Bifulco M. Prenyltransferase inhibitors induce apoptosis in proliferating thyroid cells through a p53-independent, CrmA-sensitive and caspase-3like protease-dependent mechanism. Endocrinology $1999 \mathbf{1 4 0}$ 698-704.

38 Robbins RJ. Statins sentence thyroid cancer cells to death rho. Journal of Clinical Endocrinology and Metabolism $2003 \mathbf{8 8}$ 3019-3020.

39 Wang CY, Zhong WB, Chang TC, Lai SM, Tsai YF, Wang CY, Zhong WB, Chang TC, Lai SM \& Tsai YF. Lovastatin, a 3hydroxy-3-methylglutaryl coenzyme A reductase inhibitor, induces apoptosis and differentiation in human anaplastic thyroid carcinoma cells. Journal of Clinical Endocrinology and Metabolism $2003883021-3026$.

40 Di Matola T, D’Ascoli F, Luongo C, Bifulco M, Rossi G, Fenzi G \& Vitale M. Lovastatin-induced apoptosis in thyroid cells: involvement of cytochrome c and lamin B. European Journal of Endocrinology $2001145645-650$.

41 Johnson BA, Iacono AT, Zeevi A, McCurry KR \& Duncan SR. Statin use is associated with improved function and survival of lung allografts. American Journal of Respiratory and Critical Care Medicine $20031671271-1278$.

42 Leung BP, Sattar N, Crilly A, Prach M, McCarey DW, Payne H, Madhok R, Campbell C, Gracie JA, Liew FY \& McInnes IB. A 
novel anti-inflammatory role for simvastatin in inflammatory arthritis. Journal of Immunology $2003 \mathbf{1 7 0} 1524-1530$.

43 Youssef S, Stuve O, Patarroyo JC, Ruiz PJ, Radosevich JL, Hur EM, Bravo M, Mitchell DJ, Sobel RA, Steinman L \& Zamvil SS. The HMG-CoA reductase inhibitor, atorvastatin, promotes a Th2 bias and reverses paralysis in central nervous system autoimmune disease. Nature $2002 \mathbf{4 2 0} 78-84$.

44 Mach F. Statins as immunomodulators. Transplantation Immunology 20029 197-200.

45 Hillyard DZ, Cameron AJ, McIntyre AH, Hadden MH, Marshall HE, Johnston N \& Jardine AG. Inhibition of proliferation and signalling mechanisms in human lymphocytes by fluvastatin. Clinical and Experimental Pharmacology and Physiology $2002 \quad 29$ $673-678$.

46 Montero MT, Hernandez O, Suarez Y, Matilla J, Ferruelo AJ, Martinez-Botas J, Gomez-Coronado D \& Lasuncion MA. Hydroxymethylglutaryl-coenzyme A reductase inhibition stimulates caspase-1 activity and Th1-cytokine release in peripheral blood mononuclear cells. Atherosclerosis 2000153 303-313.

47 Kwak B, Mulhaupt F, Myit S \& Mach F. Statins as a newly recognized type of immunomodulator. Nature Medicine 20006 $1399-1402$.

48 Heuer M, Aust G, Ode-Hakim S \& Scherbaum WA. Different cytokine mRNA profiles in Graves' disease, Hashimoto's thyroiditis, and nonautoimmune thyroid disorders determined by quantitative reverse transcriptase polymerase chain reaction (RT-PCR) Thyroid 19966 97-106.

49 McPherson R, Tsoukas C, Baines MG, Vost A, Melino MR, Zupkis RV \& Pross HF. Effects of lovastatin on natural killer cell function and other immunological parameters in man. Journal of Clinical Immunology 199313 439-444.

50 Hakamada-Taguchi R, Uehara Y, Kuribayashi K, Numabe A, Saito K, Negoro H, Fujita T, Toyo-oka T \& Kato T. Inhibition of hydroxymethylglutaryl-coenzyme a reductase reduces Th1 devel- opment and promotes Th2 development. Circulation Research $200393948-956$.

51 Chakrabarti R \& Engleman EG. Interrelationships between mevalonate metabolism and the mitogenic signaling pathway in T lymphocyte proliferation. Journal of Biological Chemistry 1991266 12216-12222.

52 Kurakata S, Kada M, Shimada Y, Komai T \& Nomoto K. Effects of different inhibitors of 3-hydroxy-3-methylglutaryl coenzyme A (HMG-CoA) reductase, pravastatin sodium and simvastatin, on sterol synthesis and immunological functions in human lymphocytes in vitro. Immunopharmacology 199634 51-61.

53 Blanco-Colio LM, Munoz-Garcia B, Martin-Ventura JL, Lorz C, Diaz C, Hernandez G \& Egido J. 3-Hydroxy-3-methylglutaryl coenzyme A reductase inhibitors decrease Fas ligand expression and cytotoxicity in activated human $\mathrm{T}$ lymphocytes. Circulation 2003108 1506-1513.

54 Sadeghi MM, Tiglio A, Sadigh K, O'Donnell L, Collinge M, Pardi R \& Bender JR. Inhibition of interferon-gamma-mediated microvascular endothelial cell major histocompatibility complex class II gene activation by HMG-CoA reductase inhibitors. Transplantation 200171 1262-1268.

55 Vollmer T, Key L, Durkalski V, Tyor W, Corboy J, Markovic-Plese S, Preiningerova J, Rizzo M \& Singh I. Oral simvastatin treatment in relapsing-remitting multiple sclerosis. Lancet $2004 \mathbf{3 6 3}$ 1607-1608.

56 McCarey DW, McInnes IB, Madhok R, Hampson R, Scherbakova O, Ford I et al. Trial of atorvastatin in rheumatoid arthritis (TARA): a double-blind randomised placebo-controlled trial. Lancet 2004 $3632015-2021$.

Received 18 January 2005

Accepted 31 March 2005 